\title{
BIOLOGÍA E INTELIGENCIA HUMANA EN XAVIER ZUBIRI
}

\author{
Sergio Rodero \\ (Universidad de Granada)
}

\section{Introducción}

El problema que nos ocupa puede enfocarse desde la biología o desde la propia filosofía; más en general, puede ser enfocado desde varias ciencias positivas (biología y psicología, ambas en sus distintas variedades) o desde una filosofia de la inteligencia y del hombre. No se trata de dos planteamientos excluyentes y menos en tipos de pensamiento como el de Zubiri, que es el que se va a emplear en este trabajo ${ }^{1}$, mas no son tampoco dos planteamientos idénticos, aunque el filosófico debe tener muy en cuenta lo que diga el científico, so pena de estar elucubrando sobre el vacío.

Biólogos y psicólogos han mostrado y siguen haciéndolo que no se trata de un pseudo-problema filosófico, sino que, al contrario, se trata de un problema real, planteado por los datos de la observación y de la experimentación más rigurosa y, sin cuya contestación, el propio intento científico queda cumplido a medias ${ }^{2}$.

${ }^{1}$ I. Ellacuría, "Introducción crítica a la antropología filosófica de Zubiri", Realitas II, Madrid, 1976, pp. 49-137.

2 Como comprobación de este punto y como aporte bibliográfico básico ténganse presentes estos textos: E.D. Adrián, La base de la sensación, Madrid, 1947; E.D. Adrián, The physical background of perception, Oxford, 1947. J. de Ajuria Guerra, y H. Hegan, Le cortex cerebral. Etude neuro-psychologique, 2. ed., París, 1960.

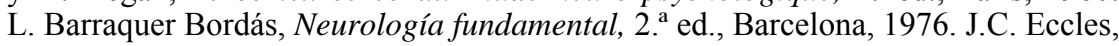
The neurophysiological basis of mind, Oxford, 1953. A.J. Lloyd (Ed.), Cerebral mechanisms in behaviour, New York, 1951. J. Piaget, Biología y conocimiento, México, 1975. J.M. Rodríguez Delgado, Control físico de la mente, Madrid, 1972. J. Rof Carballo, Patología psicosomática, 3. ${ }^{a}$ ed., Madrid, 1955. C. Sherrinton, El hombre en su naturaleza, Madrid, 1947. AA.VV., Brain mechanisms and consciousness, Oxford, 1954. La bibliografía sobre este tema es ingente. En la aquí reca-

Philosophica, 33, Lisboa, 2008, pp. 19-42 
En este texto se hará un estudio filosófico, que teniendo en cuenta los frutos de la biología y de la psicología, se enfrente filosóficamente con el problema. Como ya se sabe, Zubiri desde hace muchos años ha tratado el asunto con rigor. Lo que aquí se expondrá son los resultados últimos de su filosofía, aún inacabada, mas ya con respuestas esencialmente definitivas ${ }^{3}$.

Dos apartados básicos tendrá esta explicación: el primero, dedicado al plano de las acciones con el nombre "intelección sentiente"; el segundo, dedicado al plano de la habitud-actividad con el nombre "inteligencia sentiente". Su misma formulación unitaria, que podría expresarse como sentir intelectivo y sensibilidad intelectiva, muestra cómo la "y" del problema en la presunta relación "cerebro y mente" debe ser anulada no por identidad, sino por unidad estructural, como ya veremos después.

\section{La intelección sentiente}

Si nos atenemos a los hechos, el comportamiento humano aparece como una unidad de momentos orgánicos y de momentos cognoscitivos. Pero es preciso describir adecuadamente esta unidad acercándose lo más posible a los hechos reales tanto por lo que tienen de intelección como por lo que tienen de sensación. A continuación vamos a ver la importancia para nuestro problema de esta recta conceptuación.

\section{El hecho y la naturaleza misma de la intelección sentiente}

La intelección es, según Zubiri, un modo de aprehensión de algo. No consiste en un darme cuenta de lo inteligido. Así como ver un color no es un darme cuenta del color, sino que el darme cuenta del color es únicamente un momento del ver, igualmente la intelección no es un darme cuenta de lo inteligido, sino que me doy cuenta de lo inteligido inteligiéndolo. Se trata primaria y formalmente no de un darme cuenta, sino de una captación, de una aprehensión. "Darme cuenta de algo es un referirme a algo en esa especie de mirada con que me estoy dirigiendo a la cosa al estar captándola"4. La conciencia no es una acto especial, sino un mo-

pitulada se hace más énfasis en lo que señalan los neurofisiólogos, si exceptuamos los aportes de Piaget. Mas varios de los autores citados, de forma especial Pribram, tienen especial cuidado de atender a lo que dicen los psicólogos, muy destacadamente los psicólogos conductistas.

3 Podemos consultar bibliografía a este respecto tanto de Zubiri como acerca de Zubiri en Realitas II, pp. 549-52.

4 Es una cita inédita de X. Zubiri. 
mento del acto de intelección; un momento que no es exclusivo de la intelección -lo tienen también otros actos humanos- y que no es tampoco exclusivo del hombre -lo tienen también los animales.

Este empeño por independizar el momento de intelección del momento de conciencia tiene un nítido valor filosófico y psicológico. Filosófico, porque significa un declarado propósito de "des-idealización" de todo el proceso cognoscitivo ${ }^{5}$; psicológico, porque abre la posibilidad de pensar una aprehensión de la realidad, que no tenga todas las características no sólo de lo que sería una conciencia refleja, sino también de una conciencia, todo lo atemática que se desee, mas demasiado idealmente consciente. Es un punto de vista que podría auxiliar a neurofisiólogos y psiquiatras que trazan la relación entre mecanismos cerebrales y conciencia como si ése fuera el problema radical o que de una manera más positiva se hacen fuertes en la aceptación de aprehensiones no conscientes.

Dejando, pues, en un segundo plano el problema de la conciencia, pues lo que interesa en la intelección no son tanto los contenidos de conciencia, sino la aprehensión misma, aparecen en la intelección dos momentos diferentes: lo que se aprehende en ella y el modo como se aprehende o capta, el modo como se presenta lo aprehendido o captado. Si partimos de la captación de una cualidad sensible -dejemos de lado tanto el problema de la realidad de las cualidades sensibles como el problema de en qué conjunto y de qué forma se capta la cualidad sensible-, es fácil distinguir entre su contenido específico: rojo, amargo, extenso, etc., y la formalidad con que ese contenido se me presenta, se me da.

Vamos a analizar más de cerca este problema de la formalidad, pues en él reside la clave de lo que es la intelección humana. La similitud entre lo que le sucede al animal en sus aprehensiones y lo que le acontece al hombre en las suyas, nos pondrá en la pista y nos servirá de hilo conductor para desenmascarar nuestro tema de "biología e inteligencia". Y es que el mismo contenido se presenta según formalidades diferentes en el hombre y en los animales, siendo, por ende, la "formalidad" lo que imprime su carácter al acto en cuestión.

El animal también aprehende, pero lo aprehendido por él lo es sólo en forma de estimulación. Que algo sea estímulo significa que "suscita" una respuesta. No sólo una reacción físico-química que responde mecánicamente a una acción, sino una estricta "respuesta"; por ejemplo, que el león hambriento se lance sobre su presa, como acción entera suya, aunque a partir de las reacciones físico-químicas, etc., y apoyado en ellas. Tampoco puede confundirse la respuesta con el resultado de una mera excitación, que puede ser un mecanismo de respuesta, pero no la respuesta misma. En la estimulación propiamente dicha responde el animal entero

5 D. Gracia, "Materia y sensibilidad”, Realitas II, pp. 203-243. 
como unidad total, aunque esto no implique que todo él sea igualmente activo en la respuesta ${ }^{6}$.

Mas el puro estímulo no solamente suscita una respuesta, sino que la suscita afectando al animal a modo de impresión. "Impresión es, por lo pronto, "afección". El objeto afecta físicamente a los sentidos. Cuando Aristóteles desea establecer una distinción entre la inteligencia (noûs) y el sentido (aísthesis), caracteriza a la inteligencia como algo "inafectado" (apathés). La inteligencia puede ser pasiva, pero es impasible, no sufre afección física como los sentidos. La filosofía moderna ha tomado este concepto de impresión como afección. Y como toda afección es subjetiva, lo sensible, como mera afección del sujeto queda desligado de lo real. Todo el empirismo se cimienta en esta concepción. Mas esto es a todas luces insuficiente. Porque el ser afección no agota, no consume la esencia de la impresión. Ya desde centurias atrás se había visto que en la afección de la impresión nos es presente aquello que nos afecta. Este momento de alteridad en afección es la esencia íntegra de la impresión. Por esto las impresiones no son meramente afecciones subjetivas" ". Hay, pues, en la impresión una afección física y material, lo cual, por una parte, recalca cierta independencia del estímulo sobre lo estimulado, pero, por otra, subraya cierta identificación entre lo estimulante y lo estimulado, no sólo porque el animal estimulado ponga mucho de sí en la aprehensión estimúlica, sino porque en ella el estímulo y la respuesta forman una estricta unidad en la que se remiten uno al otro.

En el caso del puro animal, es decir, del animal no humano, el estímulo es aprehendido y captado como algo que consiste en suscitar una respuesta. Lo aprehendido es aprehendido como mera estimulación, sin que esto implique ninguna subjetivización del estímulo, porque el animal, como termino de decir, al aprehender impresivamente el estímulo, lo aprehende con un momento de alteridad, de independencia, de emancipación. El estímulo es aprehendido como algo distinto del animal, como algo "objetivo". "El animal tiene...impresiones, pero la alteridad que en

6 "The usual Newtonian and Sherringtonian chaining of agent and reaction becomes complicated by the introduction of feedback and feedforward operations. Two courses are open: to ignore the internal complexities of the system, or to account for them and deal effectively with the necessary alterations. For the most part, behaviorists have ignored the new complexity. But they can't avoid the problem that stimulus can be defined only by the response elicited, and conversely, that response can be defined fully only by the conditions that provoke it". Pribram, 1. c., p. 132. Se trata, pues, de una estricta respuesta y no de una mera reacción. Es asimismo lo que defiende Piaget y en general quienes buscan dar una explicación algo fina del fenómeno del estímulo más allá de una mentalidad cartesiana o mecanicista, aunque sin que esto signifique caer en los esquemas del vitalismo.

7 X. Zubiri, "Notas sobre la inteligencia humana", Asclepio, XVII-XVIII, pp. 344-345 . 
ellas se le da, es la de algo meramente "objetivo", esto es, distinto e independiente de la afección que sufre. El animal reconoce la voz de su dueño como algo perfectamente distinto de sus afecciones, etc. Pero esto no pasa de ser un "signo objetivo" para sus respuestas. La alteridad del animal lo es siempre y sólo de un signo objetivo. Esta objetividad no pasa de ser eso: la independencia respecto de la afección, la objetividad de un estímulo cuya afección como tal se agota en la estimulación por algo distinto del afectado. El animal puede ser y es objetivista, tanto más objetivista cuanto más perfecto sea..."

Es cierto que los estímulos pueden presentársele al animal como verdaderos signos objetivos. Por su carácter de signo el estímulo puede presentarse con características ricas y complejas, pero esta riqueza y complejidad no quita su carácter de mero estímulo, de mero suscitante de una respuesta. El signo es la cosa misma aprehendida, es cosa-signo, que en sí misma por su propia signitividad -ajena en principio a todo carácter de señalización y con mayor motivo de significación- despierta una respuesta, tanto más rica y adecuada cuanto más ricas sean las estructuras del animal. El animal aprehende el estímulo como independiente, pero sin que por eso deje de ser un puro suscitante de respuesta. El puro estímulo tiene una independencia objetiva, pero esta independencia se agota para el animal formalmente en ser suscitante y en suscitar una respuesta. Las distintas cualidades aprehendidas son distintos modos de signar respuestas, de suscitar respuestas distintas, acomodadas a la objetividad del signo respecto del animal en cuestión y de la situación vital en que se halla.

$\mathrm{Y}$ aun cuando los signos pueden presentarse al animal como señales, es decir, como referencias a algo distinto del signo, no por eso salimos del campo de la mera estimulidad. Y no salimos, en primer lugar, porque la señal se funda en lo que el signo tiene de signo $\mathrm{y}$, en segundo lugar, porque la señal lo que hace es suscitar una respuesta. El signo admite de esta manera una cierta mediación, lo cual permite un aprendizaje animal, pero no por eso deja de ser algo estimúlico, algo puramente estimúlico. El campo de lo puramente estimúlico es muy amplio y permite, gracias a la formalización ${ }^{9}$, una emancipación sobre el medio y un control sobre él por parte del animal, que cada vez es mayor a medida que se avanza en la escala animal. Pero nada de esto quita que todo el nivel de acciones del animal quede definido por la formalidad de pura estimulidad. La cosa-estímulo, la cosa-signo, suscita en él una respuesta y se agota en ser suscitación de respuesta. El animal aprehende los contenidos más diversos, según la riqueza de sus receptores y con ello complica sus signos, según

8 Ib., p. 345.

9 Sobre la "formalización” se escribirá más adelante. 
la riqueza de su formalización, pero todo lo aprehendido por él se le presenta según una formalidad típica, la formalidad de pura estimulidad.

¿Qué sucede, entonces, con el animal humano? ¿Qué acontece en ese hecho que denominamos intelección?

Lo hasta aquí dicho define lo orgánico en cuanto tal, porque aquí entendemos como orgánico lo que se da en el puro animal. El hombre participa de algunos de los elementos, que acabamos de describir. Tiene como el animal sistemas receptores, recibe estimulaciones, que le afectan y le impulsan a responder. Aprehende hasta cierto punto los mismos contenidos. Mucho es lo que de común tienen el hombre y el animal, no sólo en sus elementos estructurales, sino además en su comportamiento.

Pero los sentidos del hombre, a pesar de toda su semejanza funcional, aprehenden lo sentido de un modo peculiar, según una "formalidad" diferente. El hombre no aprehende los estímulos estimúlicamente; lo que el hom bre aprehende de los estímulos no se agota en que le susciten una respuesta actual o retardada, no se agota en las respuestas que va a desencadenar, sino que aprehende esos mismos estímulos por su cara propia, por decirlo así, por lo que son "realmente". No aprehende, por ejemplo, el calor como algo meramente calentante y suscitante de respuestas a ese su carácter de calentante, sino que lo percibe como siendo calentante, como algo a lo que compete de suyo calentar. A pesar del mismo contenido, el contenido no está aprehendido como mera estimulidad, según era el caso de los animales, sino como realidad. Si la estimulidad no es un conjunto de estímulos, sino la formalidad propia con que los puros estímulos se presentan al animal, a la formalidad propia de la aprehensión humana la deberíamos llamar reidad, porque aquí tampoco se trata primariamente de un conjunto de cosas, sino del modo o de la forma como los estímulos se hacen presentes en la intelección humana. A diferencia del puro sentir, que aprehende la cosa estimúlicamente, la aprehensión humana aprehende la misma cosa realmente.

Pues bien, la aprehensión de un contenido como reidad es el acto formal de intelección. Es un acto exclusivo de la inteligencia, porque una complicación de estímulos no dará nunca una aprehensión de algo como realidad; la diferencia entre la formalidad de estimulidad y de reidad no es gradual, sino esencial: no es que en un caso se perciban más notas o notas de diferente índole, sino que se perciben según formalidades irreductibles. Es, en segundo lugar, el acto elemental de la inteligencia, porque todo otro acto de la inteligencia como el conceptuar, juzgar, proyectar, etcétera, es siempre un modo de aprehender algo como realidad. Es, finalmente, el acto radical de la inteligencia, aquel desde el que la inteligencia es inteligencia y aquel en que todos los demás actos de la inteligencia radican. Como después vamos a ver, cuando los estímulos no son suficientes en el animal hiperformalizado para dar una respuesta adecua- 
da, el hombre suspende su actividad responsiva y, conservando la estimulación, se hace cargo realmente del estímulo, lo aprehende como estímulo real. La intelección surge formalmente en la superación de la estimulidad del sentir al aprehender el estímulo como reidad.

Nos encontramos aquí con una paradoja: por una parte, tenemos que insistir en la unidad de lo biológico y de lo intelectivo: por otra, en la peculiaridad de lo intelectivo respecto de lo biológico. Pero la afirmación fácil de la unidad negando toda diferencia entre lo uno y lo otro no hace sino desfigurar los hechos y llevar a entender la unidad como identidad. La dificultad estriba en mantener la peculiaridad de lo intelectivo, su irreductibilidad esencial y, sin embargo, conceptuar una estricta unidad, que responda a lo que es la unidad real en que se presentan en el hombre lo biológico y lo intelectivo.

Para subrayar esta diferencia Zubiri no acude a que el hombre pueda ejecutar acciones, que el animal no puede. No se fija tanto en los contenidos que el animal no alcanza, sino en la formalidad, según la cual unos mismos contenidos pueden ser aprehendidos por el puro animal y el animal humano. El atender a la diversidad de contenidos o a la peculiaridad de ciertas acciones humanas, no toca el fondo de la cuestión y lleva el peligro de des-animalizar al hombre, de des-materializarlo indebidamente; en el otro extremo, una pura diferencia de contenidos no es suficientemente radical como para especificar lo que es humano frente a lo que es puramente animal o, incluso, puramente mecánico (muchas de las dificultades cibernéticas que equiparan cerebros y computadoras con la mente humana se basan en este campo de los contenidos). Zubiri, pues, no se atiene a los contenidos, sino a la formalidad, según la cual se presentan esos contenidos al aprehensor. El punto es quizá más sutil y difícil de apreciar, sobre todo para los no habituados al discurso filosófico, pero no deja de ser el más radical. El camino de la diferencia por la formalidad va a permitir una recta conceptuación de la unidad de lo biológico y de lo intelectivo, sin reducir, no obstante, lo uno a lo otro.

¿En qué reside esta diferencia de formalidades?

Descrita ya la formalidad de "estimulidad" como aquel modo de aprehender un contenido sensible, que se agota en suscitar una respuesta, y presentada la formalidad "reidad" como aquel modo de aprehensión de ese mismo contenido sensible, según lo que la cosa es realmente de suyo, queda por profundizar en la peculiaridad de esta formalidad. Es, ante todo, lo repito otra vez más ahora, una formalidad, que se refiere al modo de lo presentado y no al contenido de lo presentado. Es, en segundo lugar, dicho negativamente, algo que no se agota en suscitar una respuesta actual o retardada. Es, en tercer lugar, que en la intelección, todo, incluso el propio estímulo, sin dejar de ser estímulo, se aprehende como teniendo en propio su carácter estimulante; no se trata de propiedades que lo fueran 
de una cosa, como si el calor fuera una propiedad de una cosa que está tras él, sino de que el calor por sí mismo es una realidad calentante; no se aprehende el calor como puro suscitante de una respuesta biológica, sino como algo que calienta de suyo. Es, en cuarto lugar, no una nota más del contenido, sino el modo mismo de estarme presente todo contenido; es que en su misma presentación se me presenta la cosa sentida como siendo en ella misma algo prius a la presentación misma, algo anterior a la presentación, pero de modo que esta anterioridad es un momento físico de lo aprehendido: es algo más que la independencia, es más que la alteridad en impresión, es la realidad como algo de suyo ${ }^{10}$; la anterioridad no es tampoco la que se da en el signo respecto de la respuesta, sino la anterioridad que hay respecto de lo aprehendido mismo: es aprehendido como calentante, sino como siendo calentante. Es, en quinto lugar, algo que al desbordar el contenido suscitante se presenta física y primariamente como algo que desborda el contenido mismo, como algo que me abre más allá del contenido actualmente presente; ese algo más no es outro contenido ni es propiamente algo que esté fuera de la cosa aprehendida, pero como formalidad de reidad me abre un ámbito que me independiza del contenido y me fuerza a separarme de él y a ir más allá de él. Lo que era cosa-signo o cosa-estímulo para el puro animal es así para el hombre cosa-realidad.

Se trata, por tanto, de dos formalidades diferentes. ¿Supone esto una separación entre lo biológico y lo psíquico en el hombre? De ninguna forma. Recordemos que la distinción se da en el orden de la formalidad y que la formalidad se presentaba en un tercer momento: donde en el animal había pura estimulidad, en el hombre había reidad. Mas existen otros dos momentos esenciales, que son comunes al puro animal y al animal humano; que son comunes, por tanto, a lo biológico y a lo intelectivo: el de la suscitación de la respuesta y el de la impresión o afección en alteridad. De ahí que el hombre no aprehenda primariamente de un modo conceptual o judicativo o sentimental, etcétera, la formalidad de reidad, sino que la aprehende impresivamente. El hombre lo que tiene es impresión de realidad, impresión de reidad; lo que en el animal es impresión estimúlica es en el hombre impresión real, que como impresión tiene todas las características positivas de la animalidad. La intelección humana es así formalmente sentiente.

¿Qué es esta impresión de reidad y cómo caracteriza la unidad primaria de la intelección sentiente?

Toda impresión, ya lo hemos visto, es una afección del impresionado; hay impresión cuando los sentidos quedan físicamente afectados, cuando hay pasibilidad física. En la afección de la impresión nos es pre-

10 C. Baciero, “Concepción metafísica del de suyo”, Realitas II, p. 313. 
sente aquello que nos afecta con un momento de alteridad. En esto no hay diferencia alguna entre el animal y el hombre: ambos aprehenden impresivamente. Que el animal lo haga según la formalidad de estimulidad y el hombre según la formalidad de reidad, no refuta que ambos aprehendan impresivamente y que, por tanto, en el hombre lo biológico entra de lleno en lo que es su intelección, en lo que es su aprehensión de la realidad. El que sea impresión no quita, sino que posibilita y estructura el unitario carácter de la imrpesión de reidad.

En efecto, en el hombre las cosas se presentan impresivamente. Mas lo interesante para nuestro propósito es que se le presentan así no solamente los contenidos, sino la formalidad misma de reidad. El que la impresión del calor no se presente estimúlicamente, sino realmente no hace que deje de ser impresión. El hombre tiene la alteridad de realidad en afección como el animal tiene la alteridad de signitividad en afección. En la impresión de reidad aprehendo a una el contenido afectante y la formalidad asimismo afectante. Toda impresión o es estimúlica o es real; la del animal es estimúlica y la del hombre es real. No son, por ende, dos impresiones ni en el caso del hombre ni en el caso del animal: en el del animal hay una única impresión estimúlica y en el caso del hombre una única impresión real. Esto es decisivo: el hombre es afectado unitariamente por el contenido sensible y por la formalidad de reidad; intelige impresivamente, intelige sentientemente. No va por una parte lo sensible y biológico y por otra lo intelectivo. El acto es estrictamente uno. Que la intelección no se minimice a la pura sensibilidad animal no quiere decir que la intelección deje de ser formalmente sensible, porque la formalidad concreta que la caracteriza es a una la impresión-de-realidad. Tener una impresión de reidad es tener una aprehensión unitariamente sentiente e intelectiva; no hay dos actos, uno de sentir y otro de inteligir lo ya sentido, sino un solo acto unitariamente sentiente e intelectivo, un acto de sentir lo sentido como real. Es un acto de sentir intelectivo o de intelección sentiente. La impresión-de-reidad es una unidad intrínseca y formal de contenido y formalidad. El mero contenido sensorial se nos presenta en impresión como siendo impresivamente ya algo de suyo, de manera que la misma inmediatez que hay en la aprehensión del contenido, la hay en la aprehensión de la formalidad de reidad.

De ahí, concluye Zubiri, la unidad de la intelección sentiente es una unidad estructural, sistemática. Inteligir y sentir son solamente dos componentes de una única estructura que ejecuta un acto único, complejo, pero uno, el acto de intelección sentiente. No se trata de una mera continuidad entre inteligir y sentir ni de una unidad objetiva en el sentido de que ambos versaran sobre el mismo objeto, sino de una unidad formal estructural. La componente sentiente es la presentación impresiva del contenido del acto, aquello por lo que las cosas se nos presentan; la com- 
ponente intelectiva es, en el sentir humano mismo, la componente modal de la impresión, la formalidad de reidad. Dicho de un modo llamativo y metafórico, Zubiri há escrito que la retina está inmersa en la inteligencia y que la inteligencia está inmersa en la retina; todo el sistema visual está inmerso en inteligencia y la inteligencia está inmersa en el sistema visual, de modo que todo lo que afecta a éste afecta a aquélla también. Con todo en general, todo lo que afecta a lo biológico, afecta a lo psíquico. Mas lo afecta porque forman una sola estructura y no porque uno "influya" sobre el otro, manteniendo la dualidad de actos y la dualidad de estructuras. Todo lo biológico es en el hombre intelectivo como todo lo intelectivo es en el hombre biológico.

La intelección sentiente, por ende, es una aprehensión impresita de realidad. No hay dualismo entre el inteligir y el sentir en la aprehensión intelectiva humana. El dualismo ontológico de sentir e inteligir, sostiene Zubiri, no solamente no es un hecho, sino que es una concepción ontológica que deforma el hecho primario de la unidad de la intelección sentiente. Ni desde el plano filosófico ni desde el plano psicológico es posible tratar los fenómenos intelectivos humanos "como si" fueran puramente intelectivos; ese "como si" deforma los hechos y puede llevar a consecuencias equivocadas. Lo aprehendido intelectivamente es primariamente un estímulo, aunque en un modo de impresión que no es estimúlico, sino real. Lo primario de la intelección no estriba en que afirme lo real como real, sino en la primaria aprehensión del estímulo como realidad. Y ése es el carácter de lo que X. Zubiri ha denominado aprehensión simple de realidad. Sobre esta aprehensión simple y desde ella, el hombre puede y necesita lanzarse a formas más elevadas de psiquismo tanto en el orden intelectivo, como en el opcional, el sentimental y el práxico, pero será siempre con ese carácter "sentiente" propio de la primaria actividad psíquica del hombre, que no es sólo primera, sino primaria y radical. La realidad se nos da primariamente en forma de impresión y no de comprensión ${ }^{11}$; vamos a ella no en forma de pura arbitrariedad libre, sino en forma opcional tendente y la sentimos no en forma de afectos espirituales, sino en forma físicamente afectante. A su vez, los sentimientos, las opciones y las aprehensiones no son puramente estimúlicos; en todos ellos se hace presente la realidad, lo cual permite un juego singular: el juego de la vida humana.

Dicho paradigmáticamente para el triple plano de la vida humana (intelectiva, sentimental y opcional), la intelección sentiente es "sentiente" porque es intelección en impresión y es "intelección" porque lo es "de realidad". Como hay una sola formalidad que es impresión-de-readidad hay también un solo acto, una sola actividad y una sola actualidad.

11 X. Zubiri, Sobre la esencia, Madrid, 1962, pp. 414-416, 451-452, 506-507. 


\section{La intelección sentiente se despliega}

Hay tantos modos primarios de inteligir como modos primarios de sentir. Es el sentir en su primaria diversidad orgánica el que va configurando los modos de inteligir, aunque luego éstos reviertan, en virtud de la unidad de la intelección sentiente, sobre los modos de sentir. Zubiri ha llevado como ninguno a sus últimas consecuencias esta unidad estructural del sentir y del inteligir en el hombre.

El pensador vasco analiza la diversidad de sentires no a partir de las cualidades que los sentidos nos ofertan: color, forma, sonido, calor, etc., sino a partir de los diferentes modos de impresión que representan. Cada sentido me presenta la realidad en forma distinta: me presenta la realidad en cuanto es intelectivo, pero en forma diferente por lo que es órganicamente como sentido. Así los diversos modos de presentársenos la realidad en los sentidos son diversos modos de intelección. Veámoslo en concreto ahora recorriendo los distintos sentidos.

El sentido de la vista, por ejemplo, aprehende la cosa real como algo que está "delante", algo que está "ante mi"; es uno de los sentidos que más ha configurado en el pensamiento de Occidente el modo de entender la intelección, como lo manifiesta la cantidad de conceptos "visuales", que utilizan nuestras lenguas para describir diferentes formas de ejercitar la inteligencia. El oído no nos hace formalmente presente la cosa sonora en la audición, sino que nos remite a ella; lo real del sonido es la presencia notificante, la presentación notificante que nos remite físicamente a la cosa de la que tenemos noticia. En el olfato la realidad aprehendida se presenta como rastro, de modo que el olfato es el sentido del rastreo. En el gusto, la cosa vuelve a estar inmediatamente presente, pero como realidad "degustada", como realidad gustante, que puede ser saboreada. En el tacto (contacto y presión), tengo la nuda presentación, la presentación de la cosa en su nuda realidad. En la kinéstesia, como sentido del movimiento, tengo la realidad como algo en "hacia", la realidad misma en hacia: es un modo de presentación direccional, porque la kinestesia es una tensión dinámica, por la que la realidad nos está presente como algo que nos lleva tensos en ella.

Igualmente, y ya respecto de uno mismo, está la aprehensión de mi realidad como atemperada a las cosas: el calor y el frío son la presentación primaria de mi realidad como atemperada. Está también la aprehensión de mi realidad como afectada: el dolor es el exponente primario de esta afección. Está asimismo la aprehensión de mi realidad entre las cosas como teniendo una posición entre ellas: es lo propio de la sensibilidad laberíntica y vestibular, que me hace sentirme como centro de las cosas y como centro de equilibrio y de orientación entre ellas. Finalmente, a tra- 
vés de la sensibilidad interna o visceral, que denominamos globalmente cenestesia, no sólo siento bienestar o malestar, sino que "me" siento bien o mal: la cenestesia nos presenta nuestra propia realidad en esa forma del "me", gracias a lo cual el hombre está en sí mismo, posee intimidad.

Después de este análisis de los sentires en cuanto formas orgánicas de aproximación a la realidad, el pensador español llega a una rigurosa conceptuación de lo que son los diferentes modos de impresión-de-reidad: presencia eidética, noticia, rastro, gusto, nuda realidad, hacia, atemperamiento, afección, posición e intimidad. Son, más allá de las cualidades o contenidos que "especifican" a cada sentido, modos primarios de impresión-de-reidad. Son en y por sí mismos modos primarios y distintos de presentación de la realidad. Es, pues, la sensibilidad la que impulsa a inteligir, la que da inicialmente los contenidos del inteligir $\mathrm{y}$, además la que diversifica y articula la riqueza de la vida intelectiva. Porque así como hay modos de sentir intelectivo, hay modos de intelección sentiente. La inteligencia, en tanto que aprehende la realidad sentida, no solamente aprehende lo sentido, sino que está en el sentir mismo como momento estructural suyo. El momento de intelección queda co-determinado por el momento de sensación, y así como hay diversos modos de sentir en virtud de la presencia estructural del momento intelectivo, así hay diversos modos de inteligir en virtud del momento sentiente.

Tratándose de la visión, la intelección tiene el carácter de representación. Por la audición, la intelección tiene el carácter de auscultación. En el gusto, la intelección es aprehensión fruitiva, la fruición degustante, como modo de aprehensión de la realidad; de ahí toda la concepción de la intelección como sabiduría. En el tacto la intelección cobra la forma de tanteo, con todo lo que esto significa de aproximación táctil y segura, pero también con lo que significa de inseguridad sobre la verdadera naturaleza de la cosa en cuestión. En el olfato, la intelección se presenta como rastreo, como persecución del rastro que dejan las cosas. En la kinestesia, la intelección es una tensión dinámica, que me impera a pasar de una realidad a otra o de un aspecto a otro de la realidad.

Respecto de su propia realidad, el hombre intelige atemperándose a la realidad y estando afectado por ella, con todo lo que esto tiene de posibilidad de aproximación, mas tambiém de intromisión de lo real en la propia realidad. La intelección de mi propia realidad como orientada y en harmonía posicional es lo que la presenta como orientación en la realidad. Finalmente, la intelección, en lo que tiene de co-determinación por la cenestesia, se presenta como intimación con lo real, la intimación misma como modo de intelección.

Queda así apuntada toda la riqueza del sentir por estar codeterminado por el inteligir y toda la riqueza del inteligir por quedar co-determinado por el sentir. Con todo Zubiri sigue adelante y se cuestiona 
por la unidad de los sentires y de la intelección; es decir, por la unidad de biología y de inteligencia.

La unidad comienza por razón del sentir mismo. Los diversos sentidos no están meramente yuxtapuestos, sino que se recubren, no en sus contenidos cualitativos diferenciados, sino en cuanto modos de presentación de lo real. Aunque no aprehendamos la cualidad propia de un sentido determinado por otro sentido, aprehendemos el modo de presentación de ese sentido en la aprehensión de otro. Así, por ejemplo, la vista y el tacto me pueden dar una presencia de la cosa como algo que está ante mi en nuda realidad. Hay también un recubrimiento entre lo modos de aprehensión de la realidad externa y los modos de aprehensión de mi propia realidad; así toda intelección de lo real externo, recubierta por la intelección en forma de intimación, hace de ella un conato de intimación con lo aprehendido.

Especial relevancia le merece al filósofo español el modo de presencia de lo real en "hacia". Revistiendo la presentación inmediata y configuracional de la vista, determina en ella un conato de visión "hacia" dentro; revistiendo la auscultación de la noticia, determina una notificación "a través" de la noticia hacia la cosa noticiada; recubriendo todo lo aprehendido en sus diversas formas, la intelección en "hacia" nos lanza a lo real "allende" lo aprehendido. Y revistiendo la sensibilidad cenestésica, determina en mi mismo nada menos que la reflexión, la cual no seria ya un momento puramente psíquico de la conciencia, sino, al contrario, algo fundado en la mismísima sensibilidad: la cenestesia, en efecto, me da mi realidad como intimidad, mediante ella me aprehendo como estando en mi; mas con el recubrimiento del "hacia" este estar en mi me lanza hacia dentro de mi propio estar en mi; esta intelección de mi propia intimidad en su "dentro" es una intelección de "mi" a través del "estar", que es en lo que consiste la reflexión. Toda reflexión presupone un previo estar en mi, el cual estar en mi es un acto de intelección sentiente; está basada en el "hacia" de mi propia intimidad, de lo cual no es ajeno el sentir, pues no se entra en sí mismo, sino sintiéndose a sí mismo.

$\mathrm{Y}$ es que los diversos sentires no conforman una diversidad primaria, de suerte que la aprehensión simple de realidad fuera una síntesis. La unidad de los sentires está constituida por el hecho de ser sentires de realidad, de ser aprehensores de la realidad. La unidad de los sentires humanos está en ser momentos de la intelección sentiente. El puro sentir animal tiene también una unidad anterior a toda síntesis: el animal es en sí mismo un viviente que siente, de forma que los sentidos son analizadores del sentir primario, como liberación biológica de las funciones de estimulación: es la unidad de estimulidad anterior a la diversidad de los sentidos. En el hombre la abolición de la unidad de estimulidad, la absorción de la unidad de estimulidad en la unidad de realidad es la constitu- 
ción formal de la inteligencia sentiente, de manera que ya no hay sentidos " $y$ " inteligencia, sino inteligencia sentiente. No se ligan primariamente las cualidades percibidas por cada uno de los sentidos, sino por sus modos propios de sentir y se unifican en la formalidad de reidad impresivamente aprehendida. Todos estos modos son modos de presentación de lo real y, en su unidad primaria y radical, constituyen los momentos modales de una única estructura y de un único acto: la estructura del aprehender sentientemente algo como real, que es la unidad primaria diferenciada en modos distintos. Estos modos son analizadores de aquella primaria unidad y por eso funcionan estructural y constitutivamente todos ellos en todo acto aprehensor de lo real.

Consecuentemente, la intelección sentiente no es un acoplamiento de sentir y de inteligir, sino que es unidad estrutural intrínseca y formal, de la misma manera que es intrínseca y formalmente "una" la impresión de reidad y la cualidad sensible. Mas en esta unidad la riqueza de la intelección sentiente no le viene de ser intelección, sino de ser sentiente. Lo que parecería ser una limitación de la inteligencia humana es el principio de su riqueza estructural. Y esto no tanto porque los diversos sentidos nos den contenidos, que de otra manera nunca tendríamos, sino más radicalmente porque nos dan diferentes modos de acceso a lo real. Qué sería, por ejemplo, una intelección que solamente se viera configurada por la presencialidad eidética de la visión? Como escribe el propio Zubiri, nuestras limitaciones no son una especie de recorte de lo que fuera la realidad, sino que esas limitaciones en su misma limitación son el principio positivo de la presentación y de la aprehensión de la realidad.

Sintetizando en unos cuantos enunciados lo expuesto en esta primera parte:

1. - El carácter biológico del comportamiento humano no es solamente evidente como hecho, sino que tiene una importancia decisiva en él, al ser no una condición ni una causa, sino un momento estrictamente constitutivo de una única estructura. En el hombre no hay de una parte intelección y de otra sensación, sino que hay un único acto que es el de la intelección sentiente.

2. - La intelección humana tiene siempre dos características esenciales del sentir biológico: la de ser respuesta y la de serio a modo de impresión. La alteridad como realidad, que es algo propio de la formalidad intelectiva es aprehendida como impresión, es aprehendida en afección. La intelección humana es sentiente no primariamente porque nada haya en ella que no haya pasado anteriormente por los sentidos, ni porque sólo pueda moverse como mezcla de datos y contenidos sensibles, sino porque la propia formalidad de reidad que la define, es aprehendida sentientemente.

3. - Hasta tal punto se da la unidad de lo biológico y de lo psíquico que, en primer lugar, el sentir queda configurado intrínsecamente por lo 
que de realidad hacen en ellos presente la codeterminación del momento intelectivo; pero, por otro lado, los modos mismos de intelección y, más en general, todos los modos de la vida psíquica están configurados por lo que tienen como más propio en cuanto sistema de receptores. La riqueza de la vida psíquica y, en el otro extremo, las malformaciones de la vida psíquica, penden en gran medida de los modos de cada sentido, de su intensidad y peculiaridad, de su conjugación, etcétera.

4. - Esto no quiere decir que el hombre quede clausurado en el mundo de lo sensible, si por sensible se entiende el ámbito de la pura estimulidad. El hombre aprehende todo materialmente, pues lo aprehende todo impresivamente; puede mantenerse, por ende, la tesis de un materialismo epistemológico, si se entiende adecuadamente este materialismo ${ }^{12}$. Pero ni el carácter sentiente, ni el carácter impresivo, ni el carácter material de la intelección humana, son óbice para que el hombre, a diferencia del puro animal, aprehenda en el sentir mismo la formalidad de reidad, irreductible en cuanto tal a todo estímulo o combinación de estímulos.

5. - Todo lo psíquico es orgánico y todo lo orgánico es psíquico en el caso del hombre. Este "es" no quiere decir identificación. Lo psíquico no es lo mismo que lo orgánico ni lo orgánico es lo mismo que lo psíquico como lo intelectivo no es lo mismo que lo sensitivo. Tampoco lo orgánico es una especie de precipitado de lo psíquico ni lo psíquico un epifenómeno de lo orgánico. Lo psíquico no anula lo orgánico, porque su asunción no se realiza a modo de anulación; tampoco lo orgánico ahoga lo psíquico. Cada uno de los momentos mantiene algunos de sus caracteres. Queda anulado en lo orgánico el momento de pura estimulidad, pero no el momento de estímulo y de estimulación; queda anulado en lo psíquico su carácter de psiquismo puro. Pero como momentos siguen manteniéndose, siguen codeterminándose y posibilitándose. Sin base orgánica desaparecería la posibilidad misma de psiquismo en cualquiera de sus formas; mas, a su vez, sin psiquismo la especie humana no sería viable con solas sus posibilidades orgánicas.

6. - En el hombre lo orgánico potencia y enriquece lo psíquico y lo psíquico potencia y enriquece lo orgánico. No cabe tratamiento alguno de cualquier problema humano sin la aceptación consciente y operante de este hecho. El planteamiento zubiriano, precisamente por partir de la más estricta materialidad y no abandonarla en momento alguno, muestra cómo el hombre no es un puro animal perfeccionado, cómo el hombre no queda encerrado en los límites de la pura animalidad. Los materialistas al uso no suelen ser capaces de profundizar debidamente en su materialismo ni de describir adecuadamente el sutil problema de la formalidad de reidad.

12 D. Gracia, "Matéria y sensibilidad", Realitas II, pp. 203-243. 


\section{Sensibilidad e inteligencia: inteligencia sentiente}

En esta segunda parte pasamos del plano de las acciones al plano de las habitudes, que participa de aquél y por la otra cara de las estructuras. El mismo título "sensibilidad e inteligencia" podría entenderse como problema estructural, pues nombra notas constitutivas de la realidad humana. Pero aquí no las vamos a estudiar en cuanto tales, sino más bien en cuanto habitudes, en cuanto modos básicos de comportamiento. Nos vamos a fijar en su carácter de habitud operativa más que en su carácter de notas constitutivas de la sustantividad humana.

¿Qué se entiende aquí por habitud? Tras el plano de las acciones, que puede definirse como el plano suscitación-respuesta se da un plano más radical, porque el tejido de respuestas no caracteriza ni unívoca ni radicalmente a ningún viviente. No es lo mismo, asevera Zubiri, que un topo carezca de vista que el que un perro se vea privado de ella; en el topo es una carencia específica que responde a un organismo específico, mientras que en el perro es una estricta privación, que le posiciona al margen de su normalidad específica. Es que todo viviente tiene un modo primario de habérselas con las cosas y consigo mismo anterior a todas sus posibles suscitaciones y respuestas ${ }^{13}$ : es la habitud, en que se basa la posibilidad y el modo formal de toda suscitación y respuesta; mientras la respuesta en una situación es un problema vital, la habitud no es un problema, sino que se la tiene o no se la tiene.

Esta habitud no solamente hace que un tipo de vivientes tenga un modo específico de habérselas con las cosas, sino que hace que las cosas se le presenten según una formalidad propia. De ahí que no pueda confundirse habitud con hábito; los hábitos son resultado de una sucesión de actos y se quedan en el nivel de los actos. No así la habitud que está más allá de ellos y se debe en definitiva a la índole estructural del viviente, sea cual fuere la participación de los actos en esa estructuración. Que no dependa de los actos, se ve bien por la razón de que esos actos son los que son en virtud de la habitud, puesto que los actos no quedan constituidos formalmente por sus contenidos, sino por la formalidad en que se dan esos contenidos. Si el contenido de los actos depende esencialmente de las cosas aprehendidas, el modo de aprehender depende básicamente de las habitudes del sujeto.

En efecto, la habitud hace que la cosa quede en cierto respecto para el viviente. Este mero quedar es lo que Zubiri ha denominado actualización y el carácter de las cosas así actualizadas en este respecto es lo que ha llamado formalidad. Para nuestro propósito e interés las dos habitudes

13 X. Zubiri, "El hombre, realidad personal”, Rev. de Occidente, 1 (1963), pp. 6 yss. 
radicales son la de la sensibilidad por la que las cosas quedan ante el viviente como puros estímulos y la inteligencia por la que quedan como estímulos reales. Las mismas cosas son para el puro animal cosas-estímulos, signos objetivos de respuesta biológica, y son para el hombre cosas-realidad. La diferencia procede de la habitud radical del hombre y del animal, que hace que las cosas queden actualizadas de una manera $u$ otra. Habitud y respecto formal se corresponden, ya que el viviente está constitutivamente vertido a su medio, pero ese medio es de un tipo o de otro y posee una respectividad u otra, según sea la habitud del viviente.

Justamente el haber comprendido el problema en términos de respectividad y, por consiguiente, en términos de habitud-respecto formal, hace que quede abierto el sendero para resolver el secular problema filosófico, psicológico y biológico del apriorismo y del aposteriorismo del viviente. Sin la habitud intelectiva con lo que implica de organización funcional, etcétera, no se le presentarían al hombre las cosas como reales. Mas esto no es un apriorismo, porque lo que la habitud "hace" es meramente actualizar una formalidad, que es la formalidad de reidad, la cual es primariamente de la cosa, aunque sólo se actualice como tal para una habitud intelectiva; por este motivo no se trata tampoco de un aposteriorismo, precisamente porque lo que se da es primariamente una actualización. La actualidad de la cosa se co-actualiza en el viviente, según las habitudes de éste. Haber diferenciado la idea de actualización y de actuación, así como la idea de formalidad y de contenidos, ubica al pensamiento zubiriano en posición privilegiada para contestar a este problema.

Ver esto desde el plano de la habitud y de la actividad implica el mostrar cómo la función primaria de la inteligencia es estrictamente biológica, punto tan básico en la filosofía del pensador español. El concebir la intelección como actualización y el concebir la habitud intelectiva del ser humano en términos de inteligencia sentiente es el punto central no solamente del pensamiento de X. Zubiri sobre la inteligencia humana, sino además la clave para desenmascarar el tema que no ocupa "biología e inteligencia". Dado el carácter de esta explicación intensiva vamos a centrarnos en tres puntos.

\section{Formalización e hiperformalización}

Conocida es la importancia que el tema de la formalización ha tenido en la filosofía zubiriana desde sus primeros cursos orales ${ }^{14}$. Con todo sólo su filosofía actual ha conducido el tema a su culminación.

14 Cfr. R. Carballo, Patología psicosomática, passim. 
Si partimos de los estímulos básicos y los consideramos como signos objetivos, vemos que estos signos van constituyendo "constelaciones" objetivas, en virtud de lo cual los estímulos se autonomizan como un todo, que actúa a su vez como estímulo. Es lo que habitualmente se conoce por percepción a diferencia de la simple sensación; el animal no aprehende sólo colores, sonidos, olores, etc., sino que aprehende, por ejemplo, una presa. Pero los mismos estímulos pueden constituir distintas constelaciones perceptivas, conforme la índole del animal. Según lo mostró Katz, el cangrejo percibe la constelación presa-roca, pero puede no percibir la presa en sí misma; para el perro, en cambio, habría dos constelaciones distintas: presa y roca. La autonomización de lo percibido consiste en que la independencia compete a la constelación misma y no solamente a cada estímulo elemental. Las unidades perceptivas son organizaciones objetivas de estímulos que, al constituir unidades autónomas, forman unidades con independencia objetiva autónoma. A esta organización objetiva de estímulos, que constituye unidades autónomas de independencia objetiva, ha denominado el pensador del País Vasco formalización. "La formalización es aquella función en virtud de la cual las impresiones y los estímulos que llegan al animal de su medio externo e interno, se articulan formando en cierto modo recortes de unidades autónomas frente a las cuales el animal se comporta unitariamente... Esta función de formalización pende de estructuras nerviosas... Se trata de una función fisiológica, tan fisiológica como puede serlo la especificación de los receptores... Esta formalización aparece asimismo en el orden efector y en el orden propio del tono vital del animal"15. En otro lugar recoge Ignacio Ellacuría nueve rasgos estructurales de esta formalización de X. Zubiri: 1/ unidad formal, 2/ con figura propia, 3/ clausura propia, 4/ unidad autónoma, 5/ que puede vagar de una situación a otras, 6/ presupone articulación de impresiones, $7 /$ posibilita un comportamiento unitario, 8/ despliega esa unidad de diversos momentos enriquecidos, 9/ permite no quedar sumergido en la pura fuerza inmediata del impulso ${ }^{16}$. A estos rasgos estructurales habría que agregar el que esta función nerviosa y, por ende, nada "mental" en sí misma. El grado de formalización es algo que en principio depende del desarrollo del sistema nervioso y, en particular, del cerebro.

La formalización es, por ende, una modalización de la formalidad estimúlica, una modalización de la independencia, de la alteridad en impresión. Es un modo de la autonomización. Esta autonomización, escribe $\mathrm{X}$. Zubiri posee dos aspectos: la autonomización del contenido respecto de otros contenidos y la autonomización de la independencia de este contenido respecto del animal. La formalización es radicalmente la modula-

15 X. Zubiri, "El hombre, realidad personal", 1, c., pp. 15-16.

16 I. Ellacuría, "La idea de estructura en la filosofía de Zubiri”, Realitas I, pp. 73-77. 
ción de la formalidad estimúlica en cuanto independencia objetiva. A lo largo de la escala zoológica asistimos a una progresiva formalización, a una progresiva independización. A mayor formalización, mayor riqueza de cosas-signo y también mayor riqueza de respuestas.

El pensador vasco insiste en que no se trata de un fenómeno de adaptación, sino que es algo que pende primariamente de la índole misma del animal. La adaptación es un fenómeno de conducta y la formalización es un fenómeno de recursos biológicos. La adaptación no constituye la formalización, sino que tan sólo la expresa: es expresión de los recursos biológicos del animal. El animal que en una situación tiene que recurrir a un grado de formalización superior, no lo hace por adaptación, sino al contrario: se adapta recurriendo a estructuras biológicas que posee. En efecto, la determinación genética es una determinación procesual; la morfogénesis es procesual, pero no todo proceso vital es morfogenético. Lo cual no quiere decir que ambos procesos sean independientes, pues si la morfogénesis determina procesualmente los recursos biológicos de la formalización, el proceso vital deja su huella en el proceso morfogenético.

Zubiri es, pues, esencialmente darwinista: da mayor relevancia a los factores internos de conformación estructural que a los factores externos de adaptación. Evidentemente, la conformación estructural no es algo que suceda con emancipación de los factores externos, como tampoco la adaptación a los factores externos niega la necesidad de que esa adaptación pase a las estructuras. Mas siempre queda abierta la pregunta de por qué mudan evolutivamente las estructuras, considerado el problema en el orden de la especie. Es un problema que continúa preocupando a biólogos y psicólogos ${ }^{17}$.

En el proceso evolutivo un parámetro seguro es el de la formalización. Lo que puede suceder es que el proceso formalizador continúe tan adelante que haga inviable la pervivencia biológica de un animal super-formalizado. Esta superformalización no sería por eso cualitativamente diferente de la formalización. Habría puesto en el límite las potencialidades de la formalización, mas esta puesta al límite no habría dado paso a algo cualitativamente nuevo, sino a algo destructivo. Habría una gran emancipación, una gran plenitud de aprehensión del signo, una gran riqueza de respuestas posibles; con todo nada de esto constituye algo cualitativamente nuevo. Este animal tan super-formalizado estaría al borde o del salto cualitativo o de la destrucción biológica. Para poder continuar viviendo necesitaría del salto cualitativo y este salto consistiría formalmente en aprehender el estímulo ya no como cosa-signo, sino como cosa-realidad.

17 N. Timbergen, en El estudio del instinto, México, 1989, dedicado en gran parte al problema del comportamiento, da pistas sobre el asunto. Este mismo problema se transforma en hilo conductor del texto de J. Piaget, Biología y conocimiento, I, c. 
En este momento puramente fisiológico de superformalización o el animal tiene recursos para convertir el puro estímulo en realidad o no los tiene. Si no los tiene desaparecería antes o después; si los tiene la superformalización se convierte en hiperformalización. Y el animal hiperformalizado ya no tiene aseguradas sus respuestas adecuadas, precisamente porque no tiene signos, sino hiper-signos. Si ha de ser biológicamente viable necesita aprehender los estímulos no como signos objetivos, sino como estímulos reales. Una especie, cuyo sentir tuviera el grado de formalización del sentir humano y no tuviera inteligencia, no sería viable. No es improbable que esto haya ocurrido en el curso de la evolución; no siempre los aparatos más delicados y perfectos son los más duraderos. No obstante, según los datos que tenemos, cuando nos encontramos restos fósiles, que permiten sospechar un determinado desarrollo del cerebro y, por consiguiente, de la formalización, nos encontramos con vestigios de estricta intelección ${ }^{18}$.

Por tanto podemos concluir que por ser la hiperformalización la respuesta biológica al problema biológico presentado por la superformalización y por ser algo cualitativamente diferente de ella sin dejar de lado el proceso fisiológico de la formalización, tenemos que todo lo intelectivo es en el hombre biológico y que sin la biología de la formalización no sería posible la intelección humana. Por ello, aunque el inteligir es algo irreductible a toda forma de sentir, es algo intrínsecamente uno con la función de sentir.

\section{La primaria actividad psico-orgánica}

¿Desde cuándo puede hablarse de psiquismo en el ser humano? $\mathrm{He}$ ahí una cuestión debatida por biólogos, filósofos y teólogos. La cuestión se presenta ya en el orden filogenético, mas cobra mayor importancia para nuestro tema en el orden ontogenético. Aquí por aparición del psiquismo entendemos no una cuestión metafísica y estructural, sino una cuestión funcional, aunque la referencia a lo estructural se hace a veces ineludible.

Sabido es que los medievales propendían a pensar que la aparición era gradual: el germen humano tendría al principio una vida meramente vegetativa; después, una vida sensitiva, y posteriormente una vida intelectiva. Ni se crea tampoco que ha sido sentencia unánime entre pensadores y teólogos a lo largo de siglos que la aparición del "alma" en el hijo se haya logrado con independencia total de los padres, como si éstos no

18 M.D. Leakey, Olduvai Gorge. Excavations in Beds, I \& II, 1960-1963, Cambridge, 1971. 
pusieran más que el cuerpo y fuera Dios quien por un acto estrictamente creativo introdujera el alma, como espíritu, en un cuerpo debidamente dispuesto. El denominado traduccionismo en formas muy variadas es algo que viene desde Tertuliano hasta Rahner ${ }^{19}$, si es que no damos al término un sentido estrecho y aglutinamos en él a todos cuantos no dejan de lado la participación activa de los progenitores en la producción del psiquismo humano. La cuestión posee gran relevancia para nuestro tema: si el psiquismo aparece con total independencia del organismo, se propenderá a atribuirle una independencia operativa, que deja a lo orgánico como pura ocasión, condición, causa instrumental, etcétera; si, al contrario, surge desde el propio organismo, la unidad será muy diferente.

Esta actividad orgánico-psíquica, no solamente es genética y estructurante, sino que es gradual: la entrada en función de cada nivel no sólo viene del precedente, sino que en su ejercicio mismo se encuentra fundado en él. Hay una estricta subtensión dinámica ${ }^{20}$. Esta subtensión dinámica consiste en que a/ la función primera exige desde ella misma la entrada en acción de la segunda, de manera que no se da una mera sucesión de actividades, sino el despliegue funcional de una misma actividad: es una actividad que desde sí misma se despliega en distintos niveles funcionales; b/ la función primera se mantiene en el seno de la segunda, con lo cual la primera sostiene intrínseca y formalmente, aunque en medida variable, las cualidades que va a poner en juego la segunda: es la configuración del nuevo ámbito funcional.

Toda esta actividad nos conduce a una última cuestión: ¿quién o qué depende más de qué? La cuestión es compleja y no tanto en principio como en las aplicaciones. La vida humana, tanto en su dimensión social e histórica como en su dimensión individual, es asaz compleja como para responder con precisión y unívocamente a esta cuestión. En el solar de las necesidades básicas de la existencia es nítida la mayor dominancia $\mathrm{y}$, consiguientemente, dependencia de lo orgánico; en el terreno de lo que podemos denominar la plenitud de la vida humana, mudan las cosas. Y es relevante mantener esta diferenciación no solamente en este asunto, sino en otros muchos. No lo más necesario es lo más indispensable; no lo más urgente es lo más hondo. Confundir la necesidad con la totalidad es muchas veces reducir al hombre y, por ende, dejar sin solución los problemas de la vida humana.

19 Cfr. manuales escolásticos. Cfr. igualmente Lexicon für Theologie und Kirche en los pasajes correspondientes, y K. Rahner, Das Problem der Hominisation, Freiburg, 1961.

20 Cfr. X. Zubiri, Sobre la esencia, 1, c., p. 365. 


\section{Actividad del cerebro "y" actividad de la mente}

En este epígrafe se abordará lo que no es sino una ejemplificación de lo que hemos venido tratando anteriormente. Es en estos términos de mente y de cerebro como suelen plantear con frecuencia la cuestión los neuro-fisiólogos. Así planteada pertenece al plano de las estructuras, cuyo estudio no hemos tratado en este trabajo. Pero nos vemos obligados a lindarlo, como en los apartados precedentes, pues así lo exige el propio carácter de la habitud. No podemos entrar en similitudes con Sherrington, Eccles, Pribram, Rodríguez Delgado, etcétera, sino que nos reduciremos a exponer el pensamiento de Xavier Zubiri.

El pensador vasco ha abordado este problema bajo el título "actividad cerebral y actividad mental"21. Por los motivos expuestos en el análisis de lo que es la intelección sentiente y la habitud y actividad intelectiva, Zubiri sostiene que el cerebro no es el órgano productor del psiquismo, sino que es el órgano que, desde la actividad psico-orgánica sensitiva, abre la entrada en acción a lo "superior" de un psiquismo, ya preexistente desde el plasma germinal. La actividad psico-orgánica en que el hombre consiste produce "a una" desde sí misma la conformación orgánica de un cerebro y la posibilidad de entrada en acción de la mente.

$X$. Zubiri sostiene, como ya hemos señalado, que en el orden de la actividad se da siempre y solamente una única actividad orgánico-psíquica, y esto desde lo que él llama plasma germinal. Que hay psiquismo en el plasma germinal, aunque su actividad sea pasiva, se desprende de dos motivos: uno experimental, pues el psiquismo adulto aparece determinado por lo que había de orgánico en el plasma germinal; otro conceptual, pues no se ve motivo alguno de que aparezca más tarde un principio estructural ni desde el punto de vista neurofisiológico ni, menos aún, desde un punto de vista filosófico que se hace fuerte en la distinción entre la formalidad de estimulidad y la de reidad.

Si consideramos, de una vez, las dos partes de esta investigación, queda bien patente cómo el pensamiento zubiriano, al que hemos seguido en toda la exposición, defiende la unidad de lo biológico y de lo intelectivo. Mas lo defiende sin confusión de límites y sin caer en dualismos metafísicos. Nada más lejos de su enfoque que entender "sustancialmente" el problema, sea hablando de una sola sustancia sea hablando de dos principios sustanciales. Uno de sus puntos más originales estriba en sobrepasar el planteamiento sustancialista y esto no sólo en el plano de las acciones y de la actividad, sino asimismo en el plano de los principios reales, a los que en esta investigación no nos hemos podido referir.

21 Aquí sigo un inédito antropológico del filósofo vasco. 
Podría pensarse que esta presencia de lo biológico en lo intelectivo, por muy intrínseca que se pensara, quedaría reducida al plano inferior de lo humano. Podría pensarse que, al lograrse las cúspides del juicio, del concepto, de la razón y de la ciencia, lo biológico quedaría atrás. Nada más lejos en el quehacer filosófico del pensador vasco. En un texto interesante, La inteligencia humana y del que se han sacado muchas ideas para esta exposición, se verá hasta qué punto es consecuente el pensamiento de X. Zubiri con su idea esencial de que la inteligencia humana es siempre e ineludiblemente inteligencia sentiente. Lo hemos venido sosteniendo a lo largo de estas páginas y lo hemos mostrado en alguna medida. Con todo tan sólo la lectura del texto zubiriano mostrará las consecuencias que para una teoría de la inteligencia tienen sus planteamientos.

Lo tienen también para la antropología y para las ciencias y las praxis que tienen entre sus manos lo que es el hombre. Lo que han pretendido estas líneas es mostrar caminos básicos, direcciones elementales para plantear ajustadamente muchos de los problemas, que atañen a la vida y a la comprensión del hombre. Entre otros, el muy grave de la idealización y de la ideologización de la existencia humana en su dimensión individual, social e histórica. No entramos en ello. Quede aquí constancia que tanto la idealización de la existencia humana como su ideologización pueden y deben ser superadas desde estos radicales planteamientos filosóficos de la unidad de lo biológico y de lo intelectivo, de lo orgánico y de lo psíquico.

\section{RESUMEN}

El problema "biología e inteligencia", considerado filosóficamente, forma parte de un problema más amplio, que provisionalmente podría denominarse "organismo y psiquismo" y debería ser tratado desde tres puntos de vista distintos, mas estrechamente entrelazados: el de las acciones, el de la habitud-actividad y el de las estructuras. El terreno de los actos es el más aparente y se refiere a todo el enorme campo de las acciones del hombre -no distinguimos aquí entre actos y acciones-, que tejen la vida del ser humano; el terreno de las habitudes, y con él el de la actividad, es más profundo y alude al modo esencial de habérselas el ser humano consigo mismo y con lo que le circunda en las acciones que realiza; finalmente, el terreno de las estructuras es todavía más profundo -tan sólo en el sentido de más radical-y alude a aquellas realidades, de la índole que sean, por las que el hombre posee modos específicos de habérselas con las cosas y puede realizar determinadas acciones.

En este trabajo nos vamos a ceñir lo más posible al problema "biología e inteligencia" y al solar de las acciones y de las habitudes, dejando para otra ocasión el problema de las estructuras, que nos conduciría al planteamiento más englobante de "psique y organismo". Por la unidad de los tres niveles y por la unidad de lo que es el ser humano y de lo que es su actividad, en ocasiones tocaremos aspectos que 
desbordan la "inteligencia" y que desbordan también el nivel de las acciones y de la habitud.

Palabras-clave: Zubiri, biología, inteligencia humana, habitud, acción, psiquismo.

\section{RESUMO}

O problema "biologia e inteligência", considerado filosoficamente, faz parte de um problema mais amplo, que se poderia denominar provisioriamente "organismo e psiquismo" e deveria ser tratado a partir de três pontos de vista diferentes, mas estreitamente entrelaçados: o das acções, o do hábito-actividade e o das estruturas. $\mathrm{O}$ terreno dos actos é o mais aparente e refere-se a todo o enorme campo das acções do homem - não distinguimos aqui entre actos e acções -, que tecem a vida do ser humano; o terreno dos hábitos, e com ele o da actividade, é mais profundo e alude ao modo essencial de o ser humano as ter consigo mesmo e com o que o circunda nas acções que realiza; finalmente, o terreno das estruturas é ainda mais profundo - apenas no sentido de mais radical - e alude àquelas realidades, seja qual for a sua índole, pelas quais o homem possui modos específicos de as ter com as coisas e pode realizar determinadas acções.

Neste trabalho vamos cingir-nos o mais possível ao problema "biologia e inteligência" e ao campo das acções e dos hábitos, deixando para outra ocasião o problema das estruturas, que nos conduziria à proposta mais englobante de "psique e organismo". Pela unidade dos três níveis e pela unidade do que é o ser humano e do que é a sua actividade, tocaremos por vezes em aspectos que ultrapassam a "inteligência" e também o nível das acções e do hábito.

Palabras-chave: Xavier Zubiri, biologia, inteligência humana, hábito, acção, psiquismo. 